\title{
Coupling coordination of industrial parks and industrial clusters in Hexi Corridor and their spatial correlation analysis
}

\author{
Rui Lyu ${ }^{1, a}$, Zhiqiang Liu ${ }^{1, b}$ \\ ${ }^{1}$ School of Economics and Management, Lanzhou Institute of Technology, Lanzhou, China
}

\begin{abstract}
With Hexi Corridor as the study case, this study established an evaluation index system for the development of the industrial parks and industrial clusters, and used the coupling coordination model and exploratory spatial data analysis method (ESDA) to explore the evolution and spatial correlation of the coupling coordination between the industrial park and industrial clusters in Hexi Corridor from 2005 to 2017. It is found that from 2005 to 2017 , the industrial parks and industrial clusters has shown closer correlations; despite the high level of coordination, the degree of coupling remains low; the Hexi Corridor has not yet developed a growth engine for the coordinated development of the industrial parks and the clusters, and there is no county-level industrial entities that have strong stimulating power. Given the requirements of the current industrial agglomeration model for regional innovation capabilities, this study proposes suggestions for coordinated development of industrial parks and industrial clusters in Hexi Corridor.
\end{abstract}

\section{Introduction}

The Hexi Corridor possesses a strategic position that connects the regions along Eurasian Continental Bridge strategic channel and links the southwest and northwest transportation hubs. It has important industrial bases including Jiujia and Jinwu, and is an important platform for creating economic and trade logistics and industrial cooperation along the Silk Road Economic Belt. Given the low level of agriculture and industry in the value chain, the insufficient opening up to the outside world, and overdependence on policy support, this region is faced with problems as to how to give full play to its comparative advantages, adjust regional industrial structure to participate in international exchanges and competition[1], and realize complementary development of industries and independent sustainable growth[2]. The "Belt and Road Initiative" has brought the western industrial parks into the era of "post-secondary entrepreneurship". With the improvement of the supporting functions, the industrial park is seeing new opportunities in adjustment its industrial structure and the opening-up to the outside world[3]. According to the stages of development of the industrial park[4], the Hexi Corridor industrial park should open up to the western countries, re-establish the industrial chain and value chain on a global scale to transform the park from an industry-led to an innovation-led growth engine. In this study, the Hexi Corridor was selected as the research area to build an evaluation index system for the industrial park and industrial clusters. Through the coupling coordination degree evaluation model, the coupling coordination degree of the industrial park and the industrial clusters as well as their spatial correlation from 2005 to
2017 were analyzed in order to provide suggestions for coordinated development of regional industries, upgrading of the industrial park and clusters, and innovational evolution of the industrial clusters, thus developing the Hexi Corridor Industrial Park into a "leading demonstration zone" and an "incubator" for industrial development that will radiate outwards.

\section{Data sources and research methods}

\subsection{Data Sources}

The data about the industrial parks in this study were obtained from two sources: the first were data released by the relevant provincial, municipal, and county departments; the second were the research data of each parks. Due to the different establishment time of the parks, data about only 12 parks in 11 counties that meet the requirements of the subsystem evaluation system were obtained. The 12 existing parks are all national and provincial industrial parks established since 2004, reflecting the overall development level of the industrial parks in Hexi Corridor. Therefore, this study finally selected 12 parks with complete data from the park level as the basic data for the evaluation index system. The data on industrial clusters come from "Gansu Statistical Yearbook" from 2004 to 2018 and the statistical yearbooks of five cities in Hexi, as well as survey data from provincial and municipal departments of transportation, science and technology, commerce and customs.

aylr0319@163.com blzqzailushanghuang@163.com 


\subsection{Research methods}

2.2.1 Establishment of the index system: Given the availability of data, the authors referred to domestic and foreign studies to build an evaluation index system for industrial parks and industrial clusters in Hexi Corridor[57]. The entropy method was used for objective assignment. The dimensions and attributes for assessment of development of industrial parks and industrial clusters are different, and to avoid the impact of such difference on the calculation result, the min-max normalization method is used to reflect the development trend of the two subsystems.

2.2.2 Modelling: The goal of coordinated development of industrial parks and industrial clusters in the Hexi Corridor is to cultivate and upgrade industrial clusters in different parks. Parks are integrated and upgraded under regional economic integration. The integration of industrial parks and industrial clusters is a reflection of the degree of coupling and coordination between the two subsystems. A comprehensive evaluation model was constructed to obtain the coupling degree between industrial parks and industrial clusters L:

$$
\begin{gathered}
\mathrm{L}=\sqrt{C \times T} \\
\mathrm{~T}=\alpha F_{p}+\beta F_{i}
\end{gathered}
$$

where $\mathrm{L}$ is the comprehensive evaluation index of the coordinated development level of industrial parks and industrial clusters, reflecting the comprehensive development level of industrial parks and industrial clusters; $\alpha$ and $\beta$ are the pending weights, $T \in(0,1), D$ $\in(0,1)$. The Delphi method was used to consult experts, and given the guidance of coordinated development of regional industries, transformation and upgrading of industrial parks, and cultivation of industrial clusters, the authors assumed $\alpha=\beta=0.5$. As shown in (1), a larger $L$ means a greater coupling coordination degree between the two subsystems, while a smaller $\mathrm{L}$ indicates a lower degree of coupling coordination. Based on existing studies and the actual conditions of the study area[5,8-9], to make the results more intuitive, the ranking of coupling coordination degree between industrial parks and industrial clusters is shown in Table 1.

Table1. Ranking of coupling coordination degree between industrial parks and industrial clusters

\begin{tabular}{|c|c|c|}
\hline Level & $\begin{array}{c}\text { Correlation degree/ } \\
\text { coordination degree/ } \\
\text { coupling degree }\end{array}$ & Description \\
\hline I & $(0.7,1]$ & Highcorrelation/coordination/coupling \\
\hline II & $(0.55,0.7]$ & With correlation/coordination/coupling \\
\hline III & $(0.4,0.55]$ & Good correlation/coordination/coupling \\
\hline IV & $(0.25,0.4]$ & Medium correlation/coordination/coupling \\
\hline V & $(0.1,0.25]$ & Relatively weakcorrelation/coordination/ \\
coupling
\end{tabular}

2.2.3 Spatial correlation analysis: The exploratory spatial data analysis (ESDA) was used to further analyze the coupling coordination between the two subsystems. ESDA is a collection of spatial data statistical methods, depicting the spatial correlation of data indicators in the study area. The authors described the spatial characteristics of the coupling between the industrial parks and industrial clusters in the Hexi Corridor, explored its overall distribution, and determined whether the coupling between the two subsystems was spatially clustered. The Global Moran's I was used to describe the overall similarity of the coupling degree of the Hexi Corridor, calculated as follows:

$$
\mathrm{I}=\frac{\sum_{i=1}^{n} \sum_{j=1}^{n} W_{i j}\left(X_{i}-\bar{X}\right)\left(X_{j}-\bar{X}\right)}{S^{2} \sum_{i=1}^{n} \sum_{j=1}^{n} W_{i j}}
$$

where $n$ is the number of the study area, $X_{i}, X_{j}$ are the observatin values of the $\mathrm{i}$ and $\mathrm{j}$ areas, $\bar{X}=\frac{1}{n} \sum_{i=1}^{n} X_{i}$ is the mean, $S^{2}=\frac{1}{n} \sum_{i=1}^{n}\left(X_{i}-\bar{X}\right)^{2}$ is the variance value, $W_{i j}$ is the spatial weight. During the calculation, rook's adjacency criterion is selected, that is, the $\mathrm{i}$ and $\mathrm{j}$ regions have a common boundary, $W_{i j}$ is set as 1 ; otherwise, it is set as 0 . The value range of Moran's I is $[-1,1]$. A positive value indicates a positive correlation between regions, a negative value indicates a negative correlation between regions, and 0 indicates that there is no correlation between regions.

\section{Result analysis}

\subsection{Coupling coordination degree assessment}

The authors normalized the data, used the entropy method for objective assignment, and calculated the weights to obtain the development level of industrial parks (Fp) and that of industrial clusters (Fi). According to the equations, the authors obtained the correlation strength $\mathrm{Fc}$, coordination degree $\mathrm{C}$ and coupling degree $\mathrm{L}$ between industrial parks and industrial clusters in Hexi Corridor. Table 2 shows the evaluation result.

Table2. Evaluation of coupling coordination between industrial parks and industrial clusters

\begin{tabular}{|c|c|c|c|}
\hline Year & Correlation & Coordination & Coupling \\
\hline 2005 & $\begin{array}{c}0.072 \\
\text { (Weak correlation) }\end{array}$ & $\begin{array}{c}0.488 \\
\text { (Good coordination) }\end{array}$ & $\begin{array}{c}0.211 \\
\text { (Low coupling) }\end{array}$ \\
\hline 2007 & $\begin{array}{c}0.074 \\
\text { (Weak correlation) }\end{array}$ & $\begin{array}{c}0.498 \\
\text { (Good coordination) }\end{array}$ & $\begin{array}{c}0.218 \\
\text { (Low coupling) }\end{array}$ \\
\hline 2009 & $\begin{array}{c}0.084 \\
\text { (Weak correlation) }\end{array}$ & $\begin{array}{c}0.483 \\
\text { (Good coordination) }\end{array}$ & $\begin{array}{c}0.226 \\
\text { (Low coupling) }\end{array}$ \\
\hline 2011 & $\begin{array}{c}0.089 \\
\text { (Weak correlation) }\end{array}$ & $\begin{array}{c}0.496 \\
\text { (Good coordination) }\end{array}$ & $\begin{array}{c}0.237 \\
\text { (Low coupling) }\end{array}$ \\
\hline 2012 & $\begin{array}{c}0.086 \\
\text { (Weak correlation) }\end{array}$ & $\begin{array}{c}0.471 \\
\text { (Good coordination) }\end{array}$ & $\begin{array}{c}0.227 \\
\text { (Low coupling) }\end{array}$ \\
\hline 2013 & $\begin{array}{c}0.096 \\
\text { (Weak correlation) }\end{array}$ & $\begin{array}{c}0.485 \\
\text { (Good coordination) }\end{array}$ & $\begin{array}{c}0.241 \\
\text { (Low coupling) }\end{array}$ \\
\hline 2014 & $\begin{array}{c}0.092 \\
\text { (Weak correlation) }\end{array}$ & $\begin{array}{c}0.479 \\
\text { (Good coordination) }\end{array}$ & $\begin{array}{c}0.237 \\
\text { (Low coupling) }\end{array}$ \\
\hline 2015 & $\begin{array}{c}0.109 \\
\text { (Relatively weak) }\end{array}$ & $\begin{array}{c}0.489 \\
\text { (Good coordination) }\end{array}$ & $\begin{array}{c}0.261 \\
\text { (Basic coupling) }\end{array}$ \\
\hline 2016 & $\begin{array}{c}0.133 \\
\text { (Relatively weak) }\end{array}$ & $\begin{array}{c}0.493 \\
\text { (Good coordination) }\end{array}$ & $\begin{array}{c}0.287 \\
\text { (Basic coupling) }\end{array}$ \\
\hline 2017 & $\begin{array}{c}0.146 \\
\text { (Relatively weak) }\end{array}$ & $\begin{array}{c}0.512 \\
\text { (Good coordination) }\end{array}$ & $\begin{array}{c}0.306 \\
\text { (Basic coupling) }\end{array}$ \\
\hline
\end{tabular}

As Table 2 shows, the coupling and coordination between industrial parks and industrial clusters in Hexi Corridor has been continuously improved, but the overall level is limited. The rise in coupling coordination in 2013 showed an accelerating trend, indicating that with dislocation and standardized management of industrial parks, the parks' leading industries have been further 
clarified, industrial clusters have formed, and the correlation between the parks and the clusters has gradually improved. The industrial development level of the Hexi Corridor is limited. By combining regional realities, the authors set up a coupling coordination degree evaluation system. However, as the two subsystems (parks and clusters) are interlacing, dynamic, and imbalanced, the overall development level of the two subsystems is low, and the industry correlation is weak, but coordination is good, in a state of "good coordination"; the large gap between the coupling degree and the coordination degree implies the urgent need to develop these two subsystems. The industrial cluster subsystem grew slowly from 2005 to 2013, and developed rapidly in 2014. At the same time, the correlation with the industrial parks was gradually strengthened. Under the condition of stable coordination, the coupling between the parks and the clusters have improved rapidly to "basic coupling". The industry in counties in Hexi Corridor has been at a high rate of development.

\subsection{Coupling degree spatial correlation analysis}

From the perspective of spatial distribution, there is a spatial correlation between the level of coupling and coordination between the development of industrial parks and industrial clusters in Hexi Corridor. The coupling index of industrial parks and industrial clusters is selected as the observation index, and the global Moran's I test is performed by ArcGIS and GeoDa software.

Table3. Global Moran index from 2005 to 2017

\begin{tabular}{|c|c|c|c|}
\hline Year & $\begin{array}{c}\text { Global Moran } \\
\text { index }\end{array}$ & Year & Global Moran index \\
\hline 2005 & -0.2481 & 2013 & 0.2685 \\
\hline 2007 & -0.2535 & 2014 & 0.2392 \\
\hline 2009 & -0.2692 & 2015 & -0.2794 \\
\hline 2011 & -0.2783 & 2016 & -0.2824 \\
\hline 2012 & 0.2532 & 2017 & -0.2699 \\
\hline
\end{tabular}

The range of the global Moran's I value is [-1, 1], with 0 as the boundary to indicate negative correlation and positive correlation. The larger the value, the smaller the overall difference. Therefore, when the coupling coordination degree is studied, the larger value indicates that the spatial aggregation is significant and the fusion effect is good[10]. Table 3 shows the global Moran's I index for the coupling degree of industrial parks and industrial clusters from 2005 to 2017 . It is found that the coupling degree of industrial parks and industrial clusters in Hexi Corridor generally shows a negative correlation, indicating that the coupling level is spatially dispersed; and with the dispersion of the spatial distribution of counties in Hexi Corridor, the dispersion of coupling degree between industrial parks and clusters in this region becomes even more significant. This means the areas where the development level of industrial parks and industrial clusters are not coordinated are close to each other in the Hexi Corridor area, that is, the coupling areas of the parks and clusters are distributed in a dotted pattern. This spatial autocorrelation feature is a result of the industrial distribution of the Hexi Corridor. The deep processing of agricultural products, the metallurgical industry, and the new energy industry chain are short, and the industrial spatial spillover effect is weak; the radiationdriven function of the coupling of park development and industrial agglomeration has yet to be seen. Around 2009, as the rigid promotion effect of the new energy industry policies weakened, and the Hexi Corridor new energy industry structure was adjusted, and the positioning of industrial parks was upgraded, which weakened the coupling trend.

\section{CONCLUSION}

The following suggestions for policy-makers are concluded given the analyses above.

- The policy-makers should optimize the development spatial pattern of the Hexi Corridor, strengthen the function of group formation, and develop an integrated Hexi Corridor Special Economic Zone. The Jiuquan and Jiayuguan areas can, based on the parks, develop into industrial bases for important new energy, new materials, and high-load energy, new energy assembly manufacturing bases, and important business and logistics centers along the Silk Road Economic Belt. Zhangye City can, relying on Ganzhou District, with Linze County and Minle County, strengthen the role as a central hub of the Hexi Corridor, create a Silk Road Economic Belt ecological economic center to boost development of agriculture, animal husbandry and mirco- small-, medium-sized enterprises, creating a characteristic agricultural and animal husbandry production and processing trade center of Hexi Corridor Economic Zone and the Pioneering and Innovative Industry Demonstration Park along the Road. The core area of Jinchang Wuwei can, relying on the industrial parks of non-ferrous metallurgy new materials, circular economy and bonded logistics, develop a national non-ferrous metallurgy new material base and equipment manufacturing industrial base and bonded processing trade base, forming an important international logistics port along the Silk Road Economic Belt, a national circular economy demonstration base, and an industrial demonstration base open to the west for cooperative development. Based on the overall construction of the Hexi New Energy Base, policy makers should make use of the rich resources and industrial foundation of this region, coordinate the development of the wind and photovoltaic industries and related equipment manufacturing industries to promote the dislocated development of different levels and types of industrial parks, creating industries of unique features and a coordinated development mechanism. Also, the government should rely on traffic corridors, hub cities and bonded logistics centers to carry out extensive multilateral cooperation, promote the interconnection of trade between Gansu and Central Asia and Europe, and boost the transfer of eastern industries to the relevant parks in the Hexi Corridor. 
- Policy makers should promote the transformation and upgrading of traditional industries, transform and update traditional advantageous industries such as non-ferrous metallurgy, chemical industry, and iron and steel, innovate and develop new material industries, extend the industrial chain, and develop comprehensive resource utilization industries. Based on the development of wind and photovoltaic new energy, the government should support the development of thermal power and high-load energy industries, continuously improve the power transmission facilities and technology, and promote the balance of clean energy supply and demand. Also, it is necessary to optimize and upgrade the equipment manufacturing industry, combine the new energy equipment manufacturing industry to plan the leading industries of the industrial park, develop the core competitiveness of the enterprises and the parks, encourage the division of labor and cooperation near the parks, share infrastructure, advantageous brands and policies, and strengthen the economic and technological development among the parks. Meanwhile, it is essential to actively develop the modern logistics industry, combine the Silk Road Economic Belt with large commerce and Internet + , and actively develop the modern commerce and logistics industry in important transportation node areas to create an interated modern international logistics port with strong radiation aggregation functions and logistics, processing, trade, customs clearance. Also, the government should enlarge and strengthen the characteristic agriculture and animal products processing industry, center on Hexi's characteristic superior agriculture and animal husbandry, develop leading enterprises for deep processing of agricultural products, promote the development of agricultural branding, greening, large-scale, base, and externalization, and gradually form a market for Central Asia and Europe Agricultural and a supply base of livestock products.

- It is necessary to develop and strengthen characteristic industrial clusters, and enhance the clusters' innovation ability based on the parks' development positioning, continue promoting the industrial transformation of Jinchang and Jiayuguan circular economy parks, and rely on traditional superior industries to expand the nonferrous metallurgy and chemical new materials industrial clusters. Also, based on the wind and photovoltaic equipment manufacturing industry, the government should coordinate the planning and layout of national economic and technological development zones and provincial economic and technological development zones, integrate the layout of adjacent parks, and cultivate and strengthen the industrial cluster of equipment manufacturing industries, give full play to the advantages in agriculture and seed production and vegetable processing in Zhangye Oasis, and develop and strengthen the industrial clusters of agricultural and livestock products processing trade. Moreover, the government should encourage startup initiatives of small and medium-sized enterprises, and promote the development of "One Road, One Belt" entrepreneurship \& innovation clusters in Minle County and other places.

\section{Acknowledgment}

This research is supported by the project of " 2019 Gansu Provincial Higher Education Innovation Capacity Enhancement Project (2019A-147)",and “The 'Qizhi' Talent Cultivation Project of Lanzhou Institute of Technology (2018QZ-12)".

\section{References}

1. Liu Xiao and Jung Won Sonn and Wang Zheng, "Is it possible with less R\&D to get higher development? the case study of shenzhen high-tech industrial cluster," Studies in Science of Science, vol. 32, pp. 34-43, January 2014.

2. Ivan Turok, "Inward investment and local linkages: how deeply embedded is silicon glen?" Regional Studies, vol. 27, pp. 401-417, 1993.

3. Xue Wei-xian and GU Jing, "Industrial selection of high-tech industrial development zones in western region_ based on the background of the belt and road initiative," China Soft Science, vol. 31, pp. 7387, September 2016.

4. Lu Zheng and Zhang Kejun, "Interface obstructions and solving ways on stage change of state hightechnology park," China Industrial Economy, pp. 512, February 2006.

5. Xu Wei-xiang and LIU Cheng-jun, "The spatial pattern and driving force of innovation of industrial cluster and county urbanization coupled coordination in Zhejiang province" Scientia Geographica Sinica, vol. 35, pp. 1347-1356, November 2014.

6. Wang Qi and Chen Cai, "Coupling Degrees of Industrial Cluster and Economic Space of Region," Scientia Geographica Sinica, vol. 28, pp. 145-149, March 2008.

7. Gao Le-hua and Zhang Guang-hai, "Research on coupling development mechanism of urbanization and tourism industrial cluster-A case study of Shandong province," Tourism Research, vol. 3, pp. 59-66, August 2011.

8. Yang You-bao and Wang Rong-cheng and CAO Hong-hua, "Study on coupling evolution relationship between tourism industry and urbanization in old industrial cities of northeast china," Human Geography, vol. 31, pp. 140-146, February 2016.

9. Wang Wei and Sun Lei, "Coupled analysis regional innovation system and resource city industrial transformation:a case study of Tongling city," Scientia Geographica Sinica, vol. 36, pp. 204-212, January 2016. 
10. Weng Gang-min and Li Ling-yan, "The coupling coordination degree and spatial correlation analysis on integrational development of tourism industry and cultural industry in China," Economic Geography, vol. 36, pp. 178-185, January 2016. 